\title{
Real-Time Applications of the Variational Version of the Local Analysis and Prediction System (VLAPS)
}

\author{
by Hongli Jiang, Steve Albers, Yuanfu Xie, Zoltan Toth, Isidora Jankov, Michael Scotten, \\ Joseph Picca, Greg Stumpf, Darrel Kingfield, Daniel Birkenheuer, and Brian Motta
}

D ue to a multitude of factors, society has become more vulnerable to natural disasters, including extreme weather events (Smith and Katz 2013). The National Oceanic and Atmospheric Administration's (NOAA) Weather-Ready Nation initiative requires high-resolution, low-latency, and very frequently updated analyses to support situational awareness and nowcasting applications, especially for high-impact events. Analyses updated every $15 \mathrm{~min}$ at around 1-km horizontal resolution, and ensuing 0-3-h numerical forecasts, may meet the needs in severe weather (Stensrud at al. 2009), convective initiation, aviation, winter weather, hydrometeorological, and other highimpact applications.

NOAA's Local Analysis and Prediction System (LAPS) is a numerical data assimilation and forecast system designed to support situational awareness and nowcasting applications of high-impact weather events (Albers et al. 1996; Toth et al. 2012, 2014). LAPS was

AFFILIATIONS: JIANG, AlBERS, AND JANKOV-Cooperative Institute for Research in the Atmosphere, Colorado State University, Fort Collins, and NOAA/ESRL/Global Systems Division, Boulder, Colorado; XIE, TOth, AND BIRKenHeUeR*-Global Systems Division, NOAA/OAR/ESRL, Boulder, Colorado; SCOTTEN-NOAA/ NWS, Norman, Oklahoma; PICCA—NOAA/NWS, Upton, New York; STUMPF AND KINGFIELD-Cooperative Institute for Mesoscale Meteorological Studies, University of Oklahoma and NOAA/ NSSL, Norman, Oklahoma; MOTTA-Training Division, NOAA/ NWS, Boulder, Colorado

* Retired

CORRESPONDING AUTHOR: Hongli Jiang, NOAA/OAR/ ESRL/GSD, R/GSDI, 325 Broadway, Boulder, CO 80305

E-mail: hongli.jiang@noaa.gov

DOI:10.II75/BAMS-D-13-00185.I

A supplement to this article is available online (10.II75/BAMS-D-13-00185.2)

(C)2015 American Meteorological Society originally developed in the late 1980s and early 1990s (McGinley et al. 1991). As LAPS was one of the first systems to analyze diabatic processes critical for the initiation of convective and other cloud- and precipitationrelated processes, it has been widely used operationally by more than 20 national and international agencies. Some of these agencies have also partnered with the NOAA/Earth System Research Laboratory (ESRL)/ Global Systems Division (GSD) in a community effort to further develop LAPS. Since the mid-2000s, GSD has engaged in systematic research, development, and evaluation of LAPS aimed at modernizing it. Recently, GSD introduced a new version of LAPS, called variational LAPS (vLAPS) to distinguish it from earlier versions of LAPS that we will refer to as "traditional" LAPS. While traditional LAPS uses a modified Barnes analysis scheme (Hiemstra et al. 2006), the vLAPS uses a modern three-dimensional (3D) variational data assimilation (3DVAR) approach, based on a computationally efficient multigrid technique (Xie et al. 2011).

LAPS has been used operationally on the Advanced Weather Interactive Processing System (AWIPS, Etherton and Santos 2006) since 1995, and both the traditional and new, variational versions of LAPS are being transitioned into the next generation AWIPS (AWIPS-II; Raytheon 2013) for use in operations at the National Weather Service (NWS) Weather Forecast Offices (WFOs). All components needed to run the $3 \mathrm{D}$ analysis (diagnostic capability) of vLAPS are in AWIPS-II (version 1 released in July 2014) to support situational awareness. The gridded analysis can be used either as a situational awareness tool or for initializing numerical weather prediction (NWP) models to produce short-range forecasts in nowcasting applications. The vLAPS-based nowcasting-namely the use of the 3D vLAPS analyses-is an option to initialize numerical models for very short-range and finescale forecasting of convective and other severe weather (also referred to as "hot start" initialization). 
During the spring of 2013, the vLAPS underwent the first real-time tests at NOAA's 2013 Hazardous Weather Testbed (HWT; Clark et al. 2012) Experimental Warning Program (2013-EWP). The objective of EWP is to improve prediction of severe convective weather on the "warning" (0-2 h) time scale. Various meteorological products from different sources were evaluated by forecasters in real time. This paper highlights some of the new capabilities of vLAPS, evaluates its real-time performance during 2013-EWP, and discusses its strengths and weaknesses as identified by the forecasters. Some issues associated with the weaknesses have been addressed. Acronyms are listed in the appendix.

VARIATIONAL LAPS. A Brief Description of $v$ LAPS. LAPS has recently undergone a major upgrade that takes advantage of emerging new technologies in data assimilation to meet user demands. The upgrade is based on the Space and Time Multiscale Analysis System (STMAS; Xie et al. 2011), and transitions the assimilation of the basic state variables (pressure, temperature, winds, and humidity) from an objective analysis method of a modified Barnes scheme with some one-dimensional variational analysis components (Albers et al. 1996) to a 3D, multiscale variational scheme (3DVAR). The multiscale approach that was pioneered in computational mathematics applications by Briggs (1987) and adopted by Xie et al. (2011) for meteorological and oceanographic data assimilation provides significant improvements in both accuracy and computational efficiency (Yuanfu Xie, personal communication, 2014).

An important feature of vLAPS is that the multiscale technique is applied in both space and time. In space, the largest scale features are analyzed first, followed by the addition of finer spatial scale details in successive iterations. In time, multiple time frames are analyzed in a single minimization, allowing the extraction of information from frequent observations (e.g., from radars and satellites) related to rapid changes. This approach is analogous to 4 DVAR (Liu et al. 2008) except that the full constraint of an NWP model is substituted by a time filter and other simplified constraints such as that the analyzed flow at each time level must be hydrostatically balanced (weak constraint) and incompressible (strong constraint). The approach can also be compared to 4D-EnVar (ensemble-variational data assimilation), where the temporal constraints are provided by ensemble covariance information (Liu et al. 2008). The computational efficiency of the multiscale approach compared to that of the adjoint- or ensemble-based 4DVAR approaches is especially critical in nowcasting applications of vLAPS where the timeliness of NWP analyses is most crucial.

TABLE I. vLAPS data sources.

\begin{tabular}{l|c}
\hline Observations & Data frequency \\
\hline Profiler-NOAA network & $6 \mathrm{~min}$ \\
\hline Global positioning system & $30 \mathrm{~min}$ \\
\hline Aviation routine weather report & $\mathrm{I} \mathrm{h}$ \\
\hline Buoys & $\mathrm{I} \mathrm{h}$ \\
\hline Radiosonde observation & $12 \mathrm{~h}$ \\
\hline Local data such as surface mesonet data & $5-60$ min \\
\hline Aircraft Communications Addressing \& Reporting System & Continual \\
\hline Pilot reports & Continual \\
\hline Velocity-azimuth display (VAD) radar & 7 min \\
\hline National Operational Weather radar (NOWrad) & $5 \mathrm{~min}$ \\
\hline Next Generation Weather Radar (NEXRAD) & $5 \mathrm{~min}$ \\
\hline Satellite cloud drift winds & $15 \mathrm{~min}$ \\
\hline Satellite imagery & $15 \mathrm{~min}$ \\
\hline Satellite soundings & $15 \mathrm{~min}$ \\
\hline Background models & GFS (6 h), NAM (6 h), RAP(I h), HRRR(I h) \\
\hline
\end{tabular}


vLAPS Configurations. The vLAPS has two different configurations: a two-dimensional (2D) surface (Xie et al. 2011, 2014) and a 3D version (Jiang et al. 2014), both using multiple time frames. The $2 \mathrm{D}$ surface analysis is flow- and terrain-dependent, while the $3 \mathrm{D}$ version constitutes the baseline configuration implemented in AWIPS-II. The vLAPS analyses are generated at a 15 -min frequency on domains as fine as 1-km horizontal grid spacing.

Observational and Background Data Sources. As an NWP data assimilation system, the vLAPS integrates information from a wide variety of global, national, and local datasets, and short-range NWP forecast fields [i.e., background forecast options such as the Global Forecast System (GFS), the North American Mesoscale Forecast System (NAM), Rapid Refresh (RAP), and High Resolution Rapid Refresh (HRRR)] into a time series of $2 \mathrm{D}$ or $3 \mathrm{D}$ grids of meteorological variables. Table 1 lists the observational data sources ingested into vLAPS, and RAP is used for the background forecasts in this study.

NWP Model Forecasts Initialized with vLAPS. In the nowcasting applications, the Advanced Research Weather Research and Forecasting (ARW) model (Skamarock et al. 2008) was initialized with the 3D version of vLAPS analyses (including its surface variables) to produce $0-3$ - (or $0-4$ ) $\mathrm{h}$ forecasts. The forecasts' integrations used RAP forecasts as boundary conditions. We refer to these ARW forecasts as "vLAPS/ARW forecasts."

VLAPS AT 2013-EWP. The Experimental Warning Program (EWP) of NOAA HWT (Clark et al. 2012) has been conducted at the National Weather Center (NWC) in Norman, Oklahoma, every spring since 2008 (http://hwt.nssl.noaa.gov/ewp/). The 2013-EWP offered a good opportunity to test vLAPS for the first time in a real-time environment over the three-week period of 6-24 May 2013. The following subsections describe the configuration and use of vLAPS during 2013-EWP, and summarize forecaster comments on the strengths and weaknesses of vLAPS for all cases where vLAPS was commented on, covering many different days and events. This is followed by a more detailed analysis of two events: (1) a supercell event on 15 May, and (2) a damaging convective wind event on 23 May. For other vLAPSrelated user comments posted on the forecaster's blog, see the sidebars.
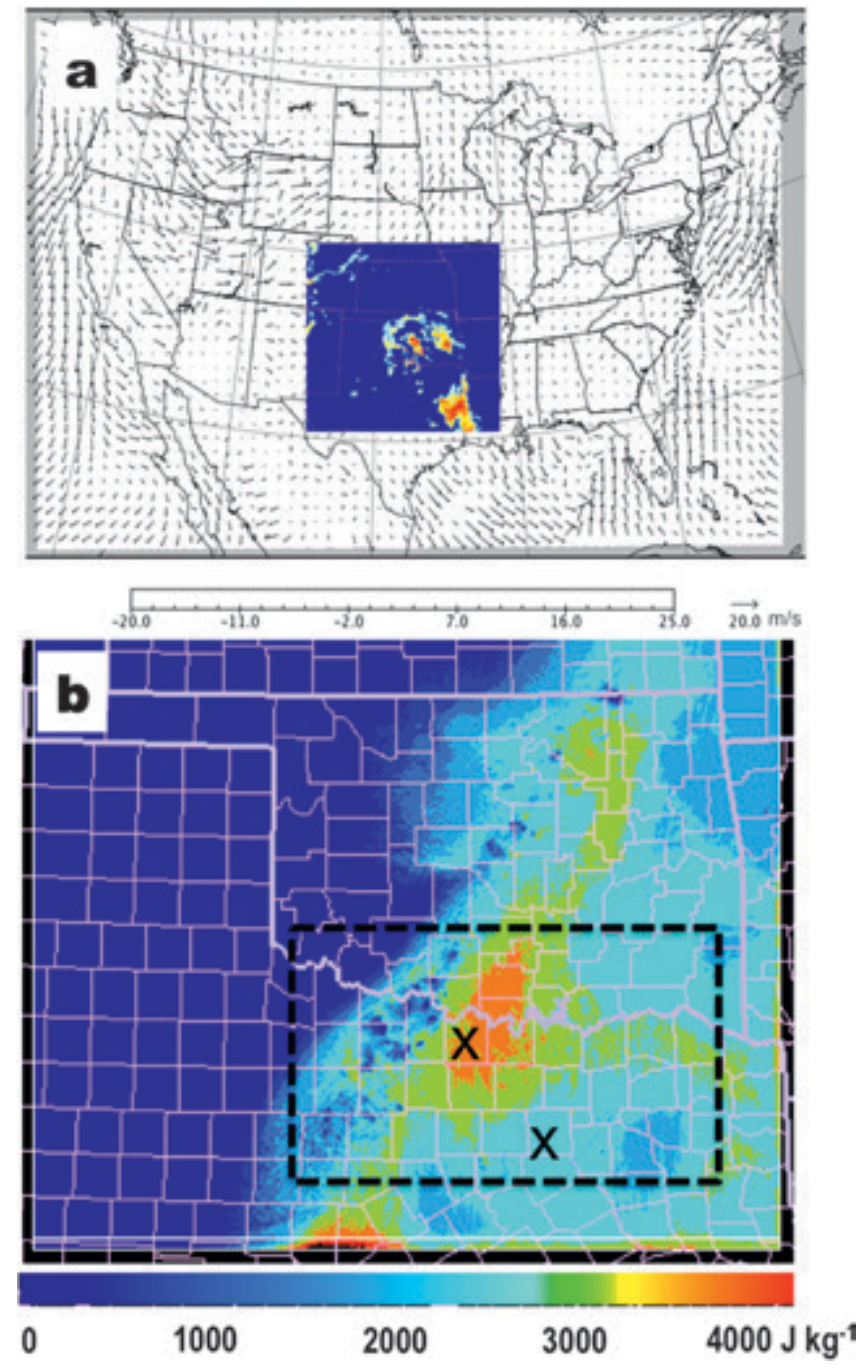

FIG. I. (a) (inset) Simulated reflectivity (dBZ) valid at 1800 UTC 15 May 2013 in $3-\mathrm{km}$ grid spacing vLAPS domain (Table 2), embedded in the $2.5-\mathrm{km}$ grid spaced 2D CONUS domain showing surface wind speed $\left(\mathrm{m} \mathrm{s}^{-1}\right)$. The CONUS domain runs the 2D configuration as summarized in Table 2. (b) Simulated SBCAPE $\left(\mathrm{J} \mathrm{kg}^{-1}\right)$ valid at 2000 UTC 20 May 2013 in I-km grid spacing vLAPS domain (Table 2). The box (thick dashed line) outlines the approximate domain location shown in Figs. 4 and 5. The $X$ on the left marks the location of highest reflectivity near Clay (CY) County shown in Fig. 4a, and the $X$ on the lower right marks the location of highest reflectivity near Dallas (DL)-Ft Worth shown in Fig. 5a.

The Configuration and Use of VLAPS in 2013-EWP. Forecasters evaluated the quality of various meteorological fields from the (2D) vLAPS surface analysis, as well as from ARW forecasts initialized with 3D 
vLAPS analyses. The 2D surface analysis was evaluated as a situational awareness, while the 3D vLAPSinitialized forecasts were evaluated as a nowcasting tool. The vLAPS applications ran over three different domains, listed in Table 2 and outlined in Figs. 1a and $1 \mathrm{~b}$. The vLAPS analyses were made available every $15 \mathrm{~min}$. Unless otherwise noted, results will be shown from the 3D vLAPS analysis and ensuing ARW forecasts.

Meteorological fields of interest (Table 2) generated and derived from the vLAPS were provided to and evaluated by the forecasters over the three-week period of HWT. Forecasters used vLAPS products, together with other available numerical guidance to issue experimental warnings. In addition, they maintained a blog for product assessments and feedback during active weather. Some forecasters tracked storm evolution and posted multiple blog entries, while others simply saved screenshots of vLAPS products.

Forecaster Evaluation of vLAPS. Out of the 15 workdays during 2013-EWP, products from 2D and 3D vLAPS were evaluated by different forecasters on 10 days. Severe weather events were reported every day during these 10 days across the continental United States. Products from the vLAPS 2D surface analysis were evaluated for situational awareness. All com- ments (five instances) were positive on the ability of the vLAPS 2D surface analysis to detect outflow and storm boundaries in the wind fields, and moisture boundaries in equivalent potential temperature $\left(\theta_{e}\right)$.

On the $3 \mathrm{D}$ nowcasting applications, there were seven instances in which the vLAPS/ARW forecast products such as the surface-based CAPE (SBCAPE) and the lifted index (LI) were valued positively, especially when combined with observed radar imagery to indicate when storms would decrease or increase in intensity with time. In five cases, the forecasters pointed out inaccuracies in either the mode, timing, intensity, or location of convective cells in vLAPS/ ARW forecast-simulated reflectivity when compared to a single radar $0.5^{\circ}$ slice. We noted that forecasts had their limitations, as one forecaster pointed out that forecast quality is a function of initial condition (vLAPS analysis) and forecast model (ARW).

A few representative samples of forecasters' comments are presented in the sidebar. The entire list of comments on vLAPS performance in both $2 \mathrm{D}$ as a situational awareness tool and 3D vLAPS/ARW forecasts for nowcasting applications are available online (http://laps.noaa.gov/hwt/20I3-ewp/20I3-EWP -blog-vLAPS.pdf). These comments were archived at NOAA's National Severe Storms Laboratory during 2013-EWP.

TABLE 2. List of domains, grid spacing, data frequency, and products used in this study.

\begin{tabular}{|c|c|c|}
\hline Domain/grid spacing & Data frequency & Products \\
\hline $\begin{array}{l}\text { Regional domain (Fig. la, inset), } 433 \\
\times 433 \text { grid points, 3-km grid spacing, } \\
\text { 3D configuration, only vLAPS/ARW } \\
\text { forecast products were evaluated for } \\
\text { nowcasting applications }\end{array}$ & $\begin{array}{l}\text { Analysis runs and updates every } \\
15 \text { min. Forecast runs } 3 \text { hourly, } \\
\text { out to } 4 \text { h, output every } 15 \text { min }\end{array}$ & $\begin{array}{l}\text { Composite reflectivity, surface- } \\
\text { based CAPE (SBCAPE), CIN, } \\
\text { lifted index (LI), updraft helicity, } \\
\text { simulated IR brightness tempera- } \\
\text { ture, cloud ceiling, cloud cover }\end{array}$ \\
\hline $\begin{array}{l}\text { Regional domain (Fig. Ib), } 80 \mathrm{I} \times 80 \mathrm{I} \\
\text { grid points, I-km grid spacing, 3D } \\
\text { configuration, only vLAPS/ARW } \\
\text { forecast products were evaluated for } \\
\text { nowcasting applications }\end{array}$ & $\begin{array}{l}\text { Analysis runs and updates every } \\
15 \text { min. Forecast runs hourly, } \\
\text { out to } 3 \mathrm{~h} \text {, output every } 15 \mathrm{~min}\end{array}$ & $\begin{array}{l}\text { Same as above. Note that even } \\
\text { though 3D configurations were run } \\
\text { in these two domains, only layer-aver- } \\
\text { aged, or integrated fields in 2D were } \\
\text { included in 20I3-EWP to reduce data } \\
\text { storage and data transfer demands }\end{array}$ \\
\hline $\begin{array}{l}\text { CONUS domain (Fig. la, back- } \\
\text { ground), 200I × } 1269 \text { grid points, } 2.5 \text { - } \\
\text { km grid spacing, 2D configuration, } \\
\text { only surface analysis products were } \\
\text { evaluated for situational awareness }\end{array}$ & $\begin{array}{l}\text { Analysis runs and updates every } \\
15 \text { min, output every } 15 \text { min }\end{array}$ & $\begin{array}{l}\text { Surface } T, T_{d}, U, V \text {, pressure, } \\
\text { and mean sea level pressure }\end{array}$ \\
\hline
\end{tabular}


Supercell Storm on 15 May 2013. An NWS Storm Prediction Center (SPC) day 1 hail outlook (Fig. 2a) issued at 1638 UTC 15 May 2013 indicated a maximum of $30 \%$ risk of severe hail-producing thunderstorms in the afternoon and into the evening for parts of Texas, east of the dryline (Fig. 2b). As the day progressed, convection-allowing model guidance (generating deep convection without a convective parameterization) valid at 2100 UTC developed deep convection and showed a $40 \%$ or greater probability for SBCAPE (Fig. 2c) greater than $2,000 \mathrm{~J} \mathrm{~kg}^{-1}$, and the supercell composite parameter (SCP; Fig. 2d, Thompson et al. 2004) greater than 1-conditions that supported supercell storm development with the possibility for large hail and perhaps a brief tornado over central Texas. The 1-km vLAPS/ARW forecast

\section{FORECASTER EVALUATION COMMENTS}

\section{On 2D vLAPS Surface Analysis as Situational Awareness Tools}

On 13 May 2013 on 2D configurations: "The $2.5-\mathrm{km}$ vLAPS did a relatively good job at resolving various boundaries that became apparent through the afternoon. Looking at the vLAPS surface dew point and wind fields across the northern Rockies around 2200 UTC . . higher terrain locations [have] lower dew points in the 20 s and 30 s ... with the lower terrain locations in the valleys and plains showing dew points in the 40 s and 50s... These both matched reasonably well with the METAR observations. The model also did well with identifying the convergence boundary in the wind fields stretching from eastern Oregon through central Montana."

On 22 May 2013 on 2D configurations: "The vLAPS products did a great job of holding fast to the idea that dry air-characterized by 30 -degree dew point depressions-was firmly [established] in places, and that any convection trying to go up would struggle mightily....The vLAPS products really make it clear that nothing substantial was to be expected. I also thought the vLAPS products did a terrific job of representing moisture boundaries well."

\section{On 3D vLAPS/ARW Nowcasting Applications}

On 8 May 20/3: “The 1900 UTC initialized vLAPS/ ARW (1-km domain, valid at 2100 UTC) appears to correctly capture some of the convection in Oklahoma and up into Kansas, but it did not accurately depict the mode of convection along the dryline. While the vLAPS forecast shows several areas of convective clusters, the radar analysis shows a line of discrete supercells."
On 14 May 2013: "In my opinion, the vLAPS surfacebased CAPE product was one of the stars of the day. Consistently, storms lived and died based on entering and exiting the tongue of higher CAPE values which extended north and northeast from the Big Bend area for most of the day." "The vLAPS data were nearly dead-on with the location, coverage, intensity, and storm mode with the storms southwest of Midland with perhaps a slight underestimation of activity near the New Mexico and Texas border."

On 9 May 2013: "The 1800 UTC 3-km vLAPS forecast of surface layer maximum base reflectivity (also referred to as simulated composite reflectivity) has done a decent job predicting the location and track of new updrafts (valid at 1945 UTC) across central Texas. Note the new individual cells developing across west central Texas on the multi-radar, multi-sensor (MRMS, online at www .nssl.noaa.gov/projects/mrms/) composite and the nearly similar forecast by the $3-\mathrm{km}$ vLAPS in both time and space. However, forecasts do have their limitations, as the forecasts produced from the initial vLAPS product are a function of the WRF. The vLAPS forecast was slower and favored individual cells within a line, rather than the complex line that developed and surged eastward."

On I6 May 2013: "Storms continue in a linear convective mode across the GLD CWA (Goodland, Kansas, County Warning Area). The 1800 UTC run of the vLAPS suggested lower instability ahead of the line as it continues to sink south. But the storms are maintaining some level of strength as they move into this supposedly more hostile environment. The GOES NEARCAST products (Note that this is a statistical, forecast product; see details online at http://cimss.ssec.wisc.edu/model/nrc/) maintained higher instability across the CWA and are probably more correct in this scenario. Just goes to show that no product is right all of the time, or even most of the time." 
initialized at 1800 UTC and valid at 2100 UTC 15 May 2013 predicted an area over central Texas with simulated SBCAPE (Fig. 3a) of 1,5002,500 $\mathrm{J} \mathrm{kg}^{-1}, 0-6-\mathrm{km}$ bulk wind differences (Fig. 3b) of $15-20 \mathrm{~m} \mathrm{~s}^{-1}$, and $0-3-\mathrm{km}$ storm-relative helicity (SRH, Fig. 3c) of $100-200 \mathrm{~m}^{2} \mathrm{~s}^{-2}$, the combination of which is commonly associated with supercells and severe thunderstorm environments. An NWS SPC tornado watch (\#161, Fig. 3d) was issued at 2100 UTC 15 May 2013 and valid between 2100 UTC 15 May and 0600 UTC 16 May 2013 for portions of southcentral Oklahoma and central and north-central Texas.

The $3-\mathrm{km}$ vLAPS/ARW 4-h forecast of simulated reflectivity valid at 2200 UTC 15 May 2013 showed the development of a large convective storm near the border of Clay (CY) and Montague (MU) counties in northern Texas (Fig. 4a). The intense convective cluster encountered a broad area of simulated SB-
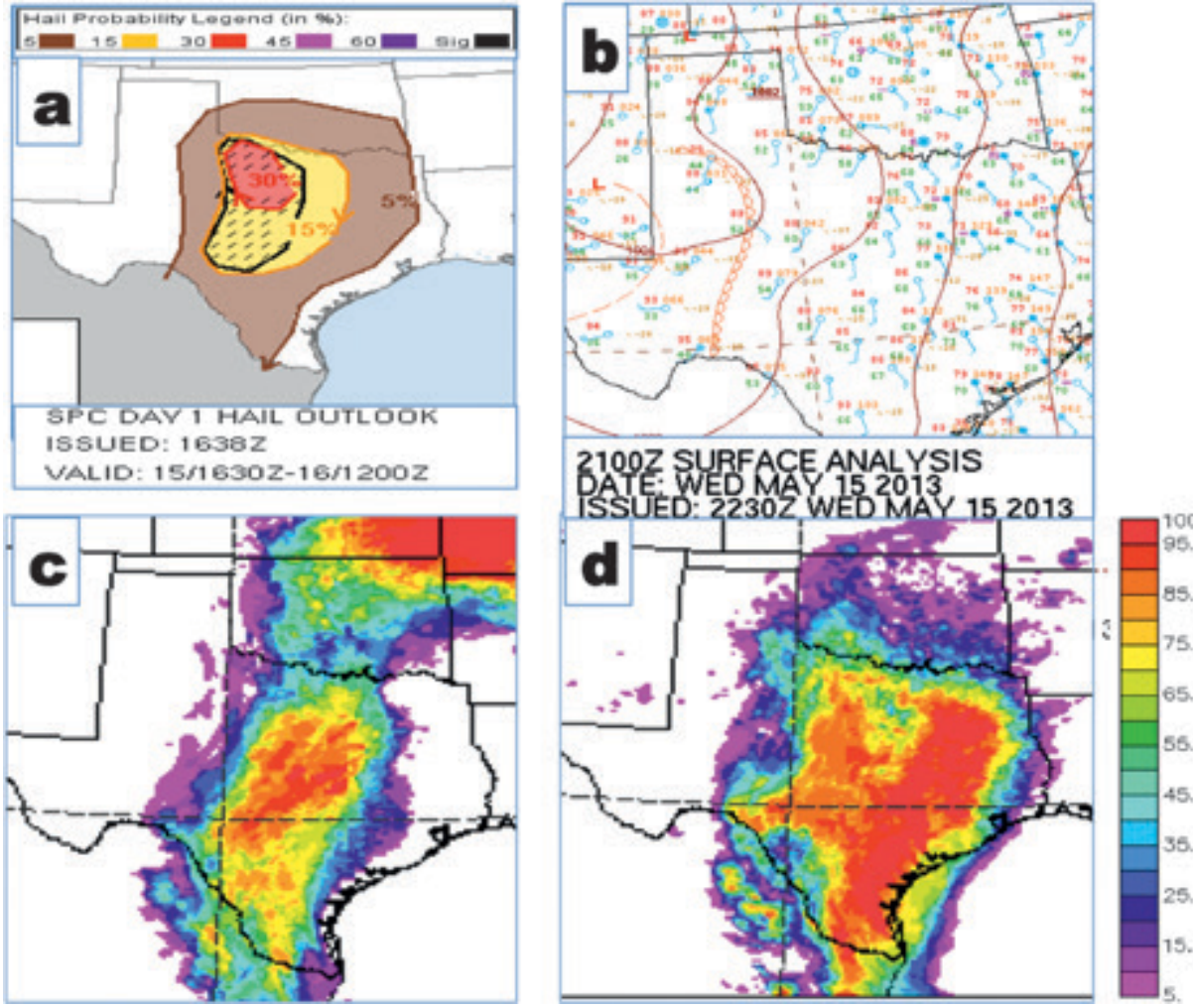

Fig. 2. Storm Prediction Center (SPC) (a) day I hail outlook issued at 1638 UTC, (b) surface analysis valid at 2100 UTC I5 May 2013, (c) probability of SBCAPE greater than $2,000 \mathrm{~J} \mathrm{~kg}^{-1}$, and (d) probability of supercell composite parameter greater than $I$ [(c) and (d) are derived from convection-allowing model guidance, courtesy of the Center for Analysis and Prediction of Storms (CAPS) at the University of Oklahoma]. The color bar (\%) applies to both (c) and (d). The surface analysis in (b) shows that there was a $20^{\circ} \mathrm{F}$ or greater difference in dewpoint temperature between the west and east side of the dryline at 2100 UTC in west Texas.
CAPE of 2,000-2,700 $\mathrm{J} \mathrm{kg}^{-1}$

located to the south-southwest (Fig. 4b). Note that the low CAPE in the northern portion of CY County was indicative of outflow. Soon after 2200 UTC, reports streamed in from storm spotters and chasers that golf ball- to baseball-size hail fell during this storm. The observed radar reflectivity image (Fig. 4c) validated the timing and placement of the 4-h vLAPS/ARW forecast storm clusters (Figs. $4 \mathrm{a}$ and $4 \mathrm{~b}$ ).

Subsequently, more storms developed to the east and northeast of the storms shown in Fig. 4. Related to those developments, forecasters reported that the 1-km vLAPS forecast captured a bow echo over southern Oklahoma and isolated supercell storms northwest of the Dallas-Ft. Worth Metroplex [south of Wise (WS) County] with 1-3 h of lead time. As an example, Fig. 5 a shows a $2-\mathrm{h}, 1-\mathrm{km}$ vLAPS/ARW simulated reflectivity of isolated supercell storms south of WS County with storm coverage and placement similar to the verifying observed radar reflectivity image (valid at 2353 UTC 15 May 2013, Fig. $5 b)$. Note that the forecast overestimated simulated reflectivity by $10 \mathrm{dBZ}$.

Additionally, the vLAPS/ARW forecast missed two significant cells in Montague (MU) County just south and north of the Red River near the Texas and Oklahoma border (Fig. 5b). The southern cell looked like a classic supercell. The SPC storm reports for 15 May 2013 confirmed two tornados in MU County at 2239 and 2358 UTC, respectively, and large hail in Jefferson (JE) County at 2305 UTC 15 May 2013. Interestingly, the vLAPS/ARW produced an extra convective cell that was not seen in the verifying radar image (valid at 2353 UTC, Fig. 5b) across Palo Pinto (PP) and Stephens (SE) counties (Fig. 5a). Hail was reported in PP 
County at 2332 UTC (about 30 min earlier than the validating radar image) 15 May 2013.

A forecaster noted that the 1-km vLAPS/ARW forecast initialized at 2100 UTC $(1 \mathrm{~h}$ earlier than that shown in Fig. 5a) indicated a potential for tornadic supercells across northwest Texas (valid from 2300 to 0000 UTC 16 May 2013), which was about 50-100 miles too far northwest of the actual location. This case serves as an example of the value in frequently updated nowcasting guidance.

Damaging Convective Wind Event on 23 May 2013. This case evaluated the $2.5-\mathrm{km}$ vLAPS surface analysis (2D configuration) for situational awareness. Two mesoscale discussions issued by the SPC at 2032 UTC (mcd0784) and 2310 UTC (mcd0786), respectively, commented that a "very large hail and damaging wind threat should remain with a supercell cluster in the eastern half of the Lubbock County Warning Area (CWA, mcd0784). The supercell over Floyd County (FL) moved slowly south and south eastward . . . supercell mergers led to convective growth in the North of Taylor County (TA) as of 2245 UTC (mcd0786, Fig. 6a)."

The surface equivalent potential temperature, $\theta_{e}$ and wind produced from vLAPS surface analysis overlaid with observed regional radar reflectivity at 2245 UTC confirmed the tornadic storm with radar reflectivity as high as $70 \mathrm{dBZ}$ in Fisher County (FS in Fig. 6b), along with a southwest to northeast-oriented convective line. This severe convective activity was propagating into the high $\theta_{e}$ area to east Nolan (NL), southeast Callahan (CA), and Brown (BR) counties (Fig. 6b).

A forecaster noted that the vLAPS surface streamline analysis at 2330 UTC indicated convergence over FS, Scurry (SC), and Borden (BD) counties, which appeared to be concentrating higher $\theta_{e}$ values in that location, likely allowing the continued development of stronger convection (Fig. 6c). In addition to high $\theta_{e}$ and convergence supportive of continued convective activity, the surface wind directions (products of vLAPS 2D surface analysis) at 2330 UTC (Fig. 6c) were
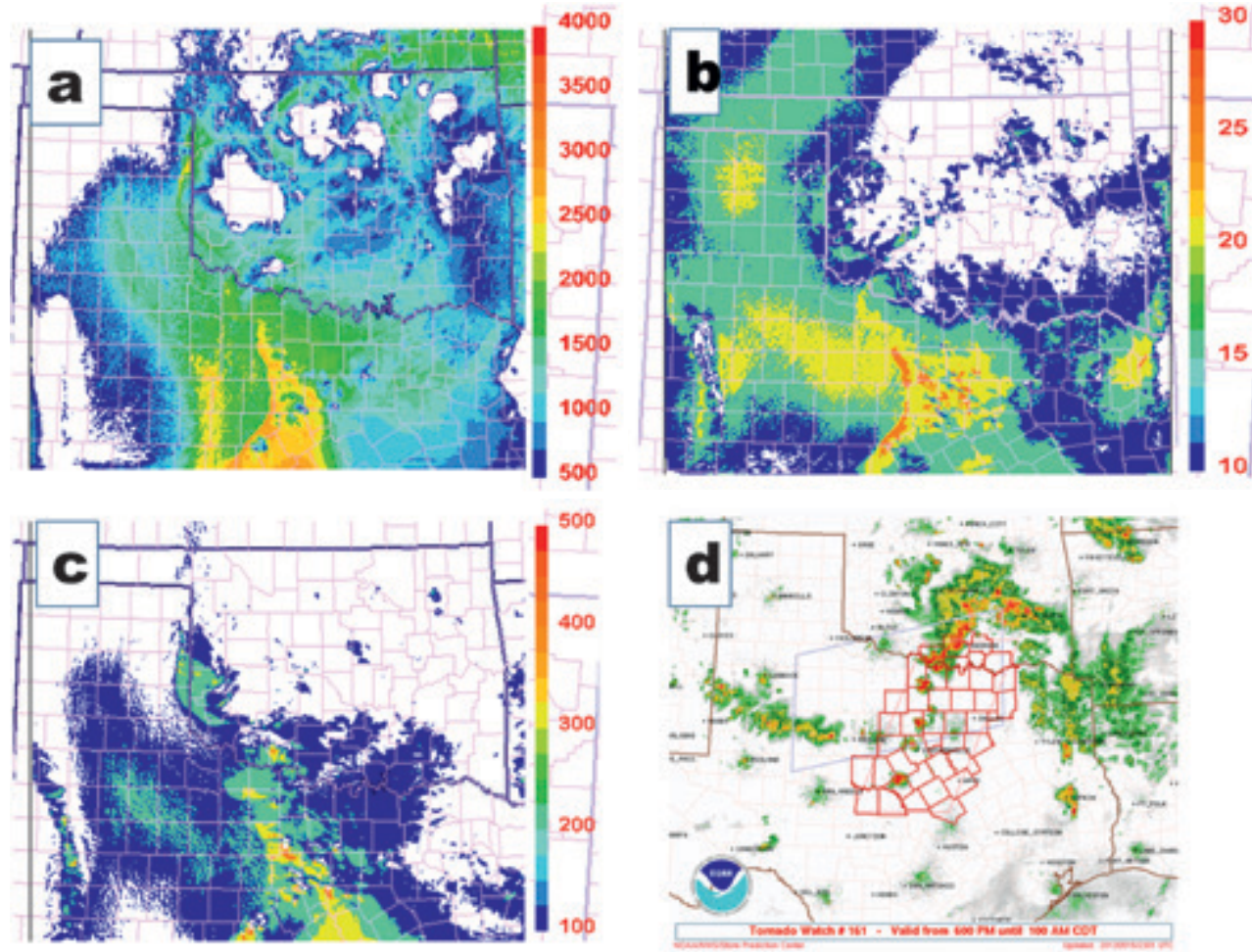

FIG. 3. Three-hour forecast from the I-km vLAPS/ARW run initialized with vLAPS 3D analyses at I800 UTC and valid at 2100 UTC I5 May 20I3. (a) Simulated SBCAPE ( $\left.\mathrm{kg}^{-1}\right)$, (b) surface to 6-km bulk wind differences $\left(\mathrm{m} \mathrm{s}^{-1}\right)$ and (c) $0-3-\mathrm{km}$ storm-relative helicity $\left(\mathrm{m}^{2} \mathrm{~s}^{-2}\right)$. (d) SPC tornado watch (\#16I) issued at $2100 \mathrm{UTC}$ and valid from 2100 UTC I5 May to 0600 UTC 16 May 2013. In (d) the counties connected in red lines mainly in Texas are referred to as the County Warning Area (CWA). in good agreement with the actual conditions (Fig. 6d, produced using http:// mesowest.utah .edu/) in the warning area at 2300 UTC, with predominantly southeasterly winds.

Summary of 2013EWP. After the completion of 2013EWP, forecasters were asked to provide some final thoughts on the experimental products. These comments are quoted below with a response from vLAPS developers, where appropriate. "The 1-km vLAPS/ARW data are tremendous at depicting storm scale subtleties in weather elements 

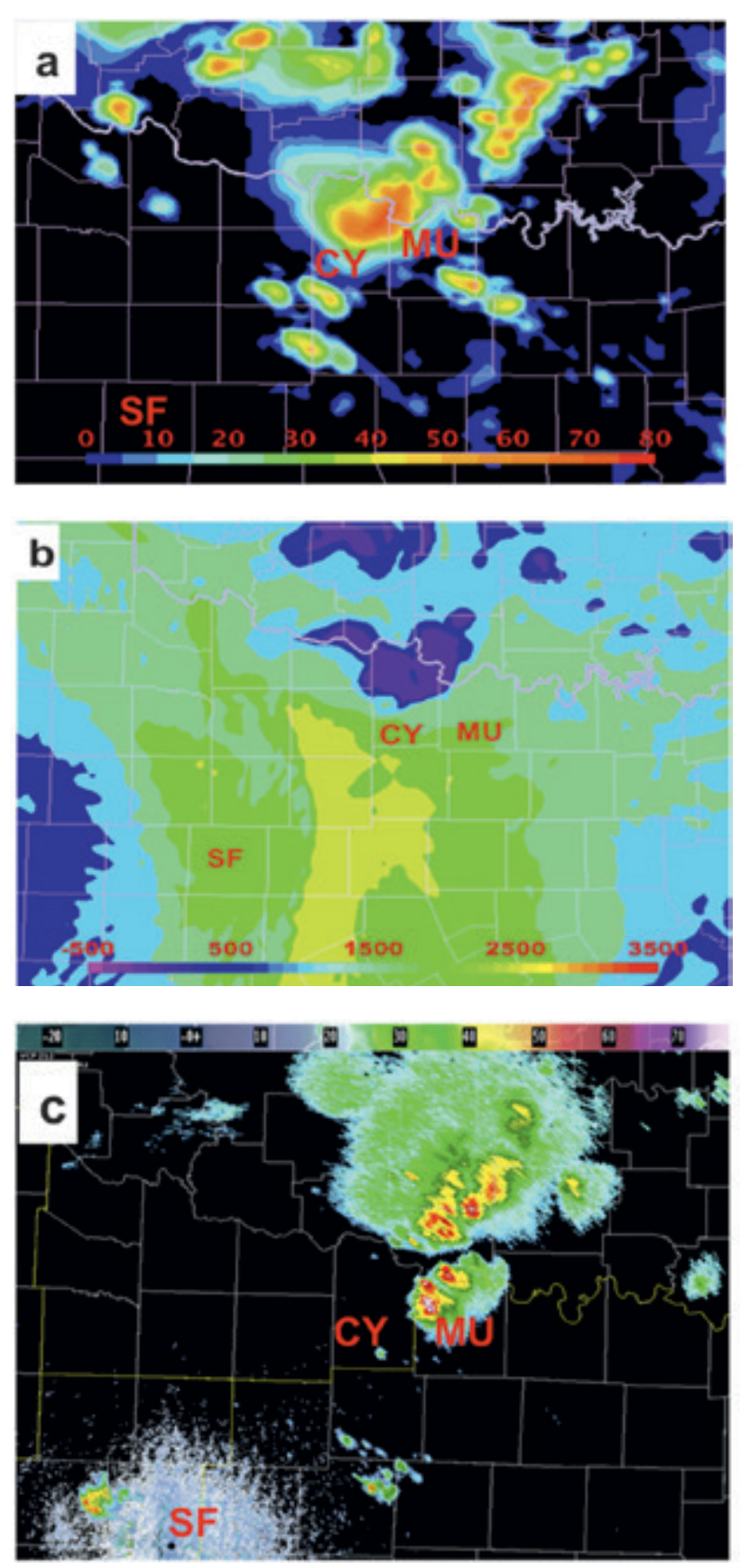

FIg. 4. Four-hour forecast from the $3-\mathrm{km}$ vLAPS/ ARW run initialized with 3-km vLAPS 3D analyses at 1800 UTC, valid at 2200 UTC I5 May 20I3. (a) Simulated reflectivity (dBZ) and (b) simulated SBCAPE $\left(\mathrm{J} \mathrm{kg}^{-1}\right)$, showing the development of a large supercell storm near the Clay (CY)-Montague (MU) County border. (c) The observed radar reflectivity image from KDYX [Dyess AFB, Shackelfold (SF) County, TX] $0.5^{\circ}$ tilt at 2204 UTC 15 May 2013 [(c) courtesy of 2013-EWP]. The domain location indicated by the box in thick dashed line in Fig. Ib. such as CAPE, LI, and surface wind; the 15 min temporal resolution of the products was valued very useful for diagnosing locations of continued convection especially in rapidly developing convective situations; the storm scale and temporal scale of variational LAPS is far superior to what is available at the WFOs right now." Two unique features of vLAPS that include the assimilation of NEXRAD radial velocity with a
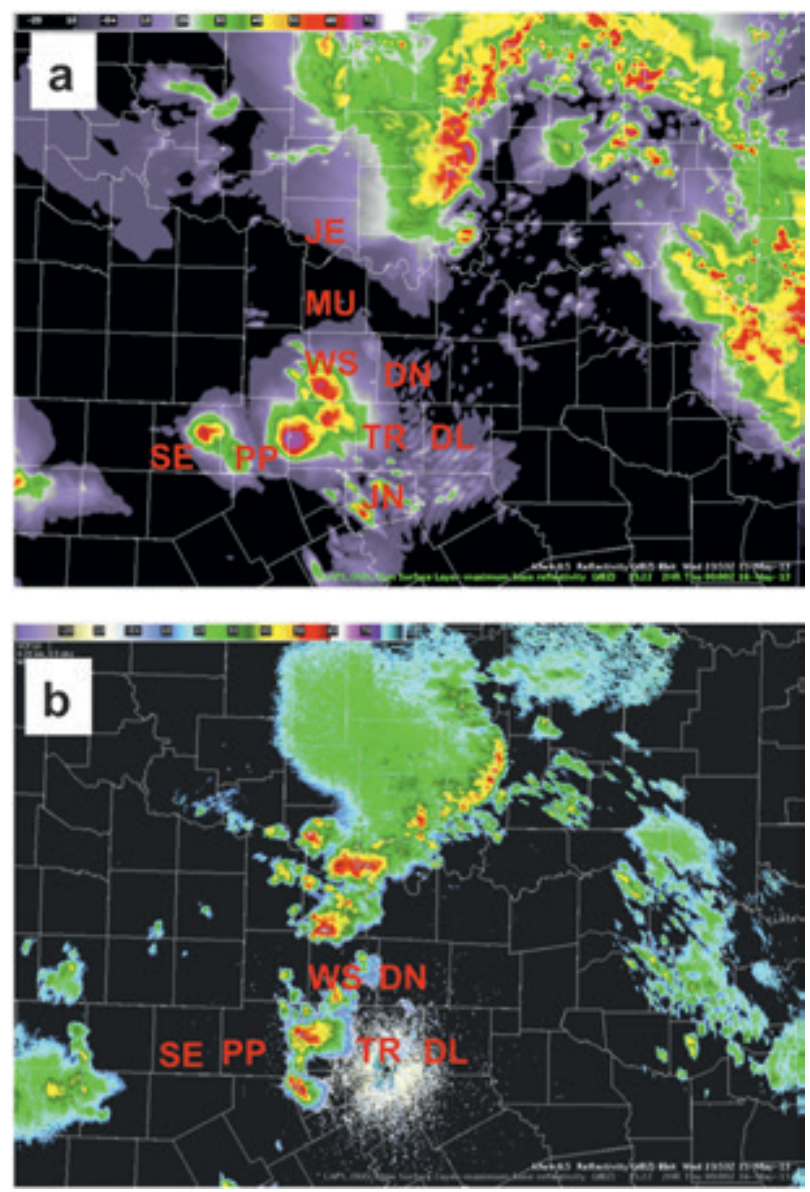

FIG. 5. Two-hour forecast from the vLAPSIARW run initialized with I-km vLAPS 3D analyses. (a) Simulated reflectivity (dBZ) valid at 0000 UTC 16 May 2013 from the 2200 UTC initialization of 15 May 20I3. (b) KFWS [Ft. Worth, TX Weather Surveillance Radar-I988 Doppler (WSR-88D) site] $0.5^{\circ}$ tilt observed reflectivity image (dBZ) at 2353 UTC I5 May 2013 [(a) and (b) courtesy of 20I3-EWP]. The western counties that belong to the Dallas-Ft. Worth Metroplex include Montague (MU), Wise (WS), Denton (DN), Dallas (DL), Tarrant (TR), Palo Pinto (PP), and Stephens (SE), with the addition of Jefferson (JE) County in Oklahoma. The most intense cell was located at Parker (PR, not labeled for clarity) County directly south of WS. 


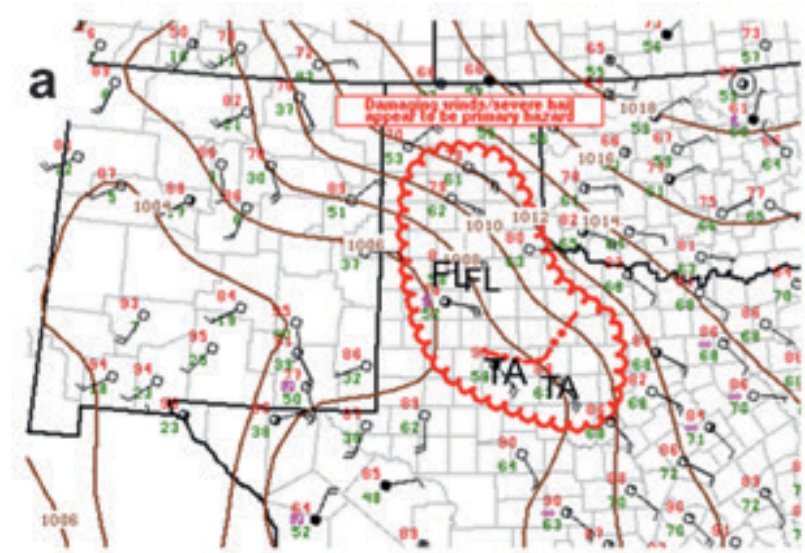

SPC MCD $\approx 0786$

issued on 2310 UTC 23 May 2013

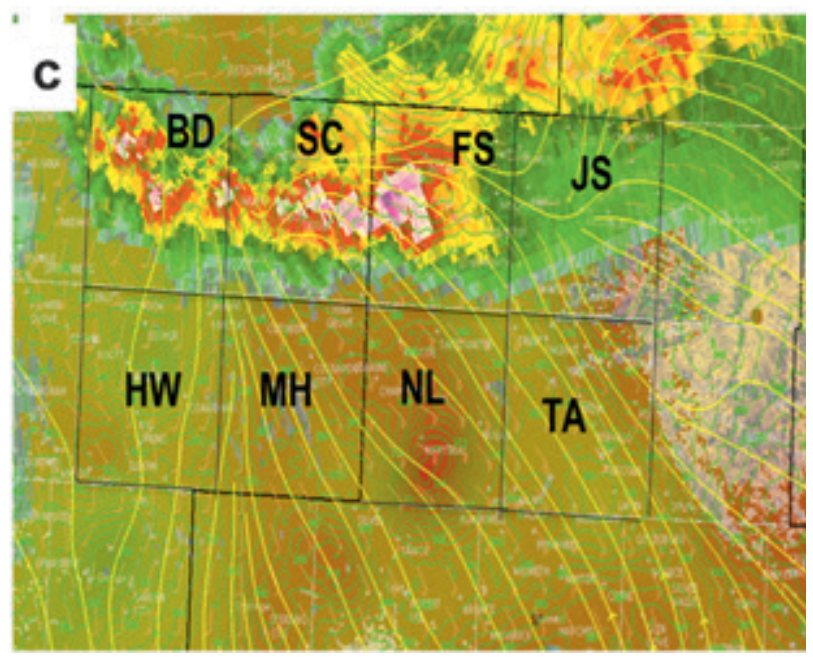

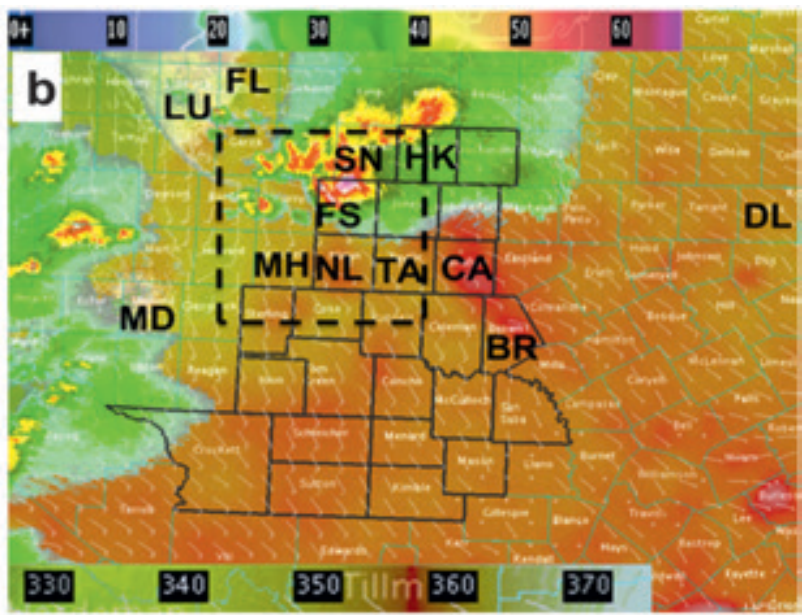

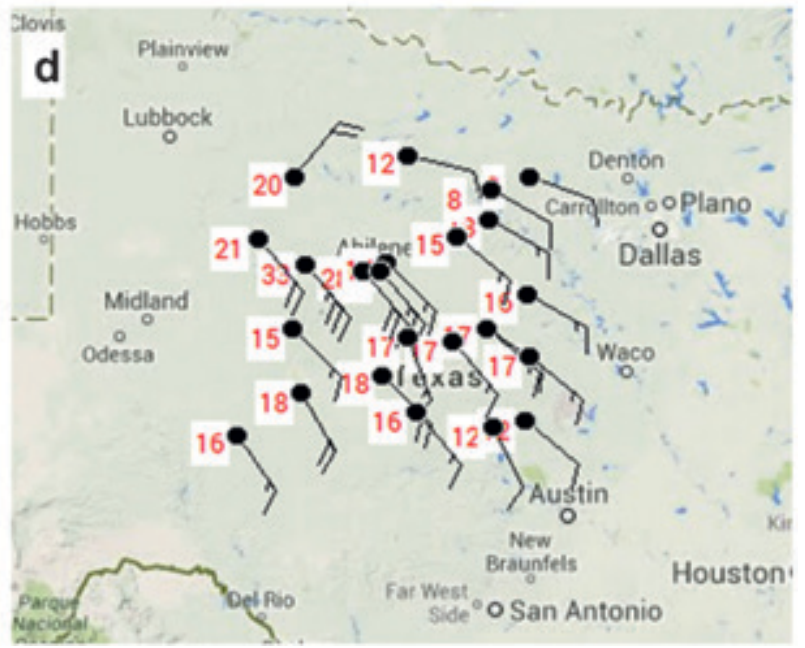

Fig. 6. (a) The mesoscale discussion (mcd0786) issued by SPC at 2310 UTC 23 May 2013. (b) and (c) are the products of the $2.5-\mathrm{km}$ vLAPS 2D surface analysis. (b) The surface equivalent potential temperature $\theta_{\mathrm{e}}$ and wind overlaid with observed regional radar valid at 2245 UTC 23 May 2013. (c) The vLAPS streamline $\theta_{\mathrm{e}}$ overlaid with observed regional radar valid at 2330 UTC 23 May 2013 with the domain location outlined in thick dashed line in (b) [(b) and (c) courtesy of 2013-EWP]. (d) The surface observations at 2300 UTC 23 May 2013 [(d) courtesy of http://mesowest.utah.edu/]. The County Warning Area was outlined in thick gray lines in (b). County labels include Borden (BD), Brown (BR), Callahan (CA), Dallas (DL), Fisher (FS), Floyd (FL), Haskell (HK), Howard (HW), Jones (JS), Lubbock (LU), Midland (MD), Mitchell (MH), Nolan (NL), Scurry (SC), Stonewall (SN), and Taylor (TA).

strong continuity constraint and the improvement of consistency between the hydrometeor and humidity analysis with a low bound constraint have improved the vLAPS over traditional LAPS in simulated composite reflectivity, and are attributable to the good performance during 2013-EWP.

Forecasters also reported that the vLAPS/ARW "overdid the storms and created too much outflow." The issue with too much outflow was likely related to the Thompson microphysical scheme used in ARW, which tended to generate more extensive regions of stratiform reflectivity and spurious convection (Clark et al. 2012). The issues associated with overdoing storm intensity, or producing an incorrect mode of convection, or missing convective cells were related to a lack of balance among humidity, cloud, and temperature in the current version of vLAPS.

VLAPS AT 2014-EWP. In response to forecaster's request for a larger domain during 2013-EWP, an 

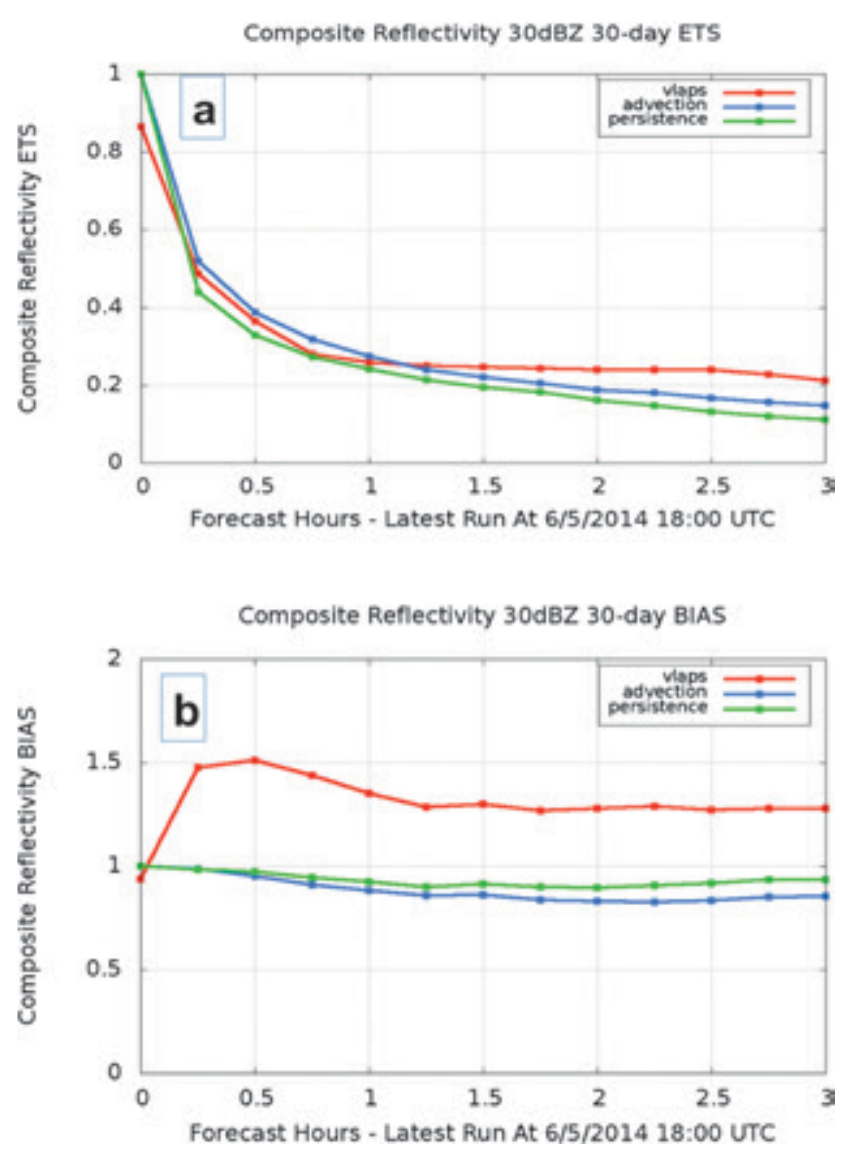

FIG. 7. The vLAPSIARW simulated reflectivity verification of (a) equitable threat score (ETS) and (b) bias score (BS) for the 30 days of the 2014 EWP (5 May-6 Jun 2014).

on-demand vLAPS with 15-min update frequency, $1-\mathrm{km}$ resolution nowcasting system (similar 3D configuration as shown in Fig. 1b), relocatable to cover high-impact weather events, was tested during 2014EWP (5 May-6 June 2014). The capability received positive remarks from forecasters, setting baseline performance statistics for future Warn-on-Forecast applications.

Since the main focus of this study is the evaluation of vLAPS performance during 2013-EWP, only limited results are presented here from the 2014-EWP experiment. As a summary measure of vLAPS performance during 2014-EWP, we will use equitable threat score (ETS) and bias score (BS) (Wilks 1995), two objective metrics commonly used to assess forecast reflectivity (simulated using the ARW hydrometeorological variables) against observations. Shown in Figs. 7a and 7b are the ETS and BS results for vLAPS initialized ARW forecasts of $30 \mathrm{dBZ}$ threshold reflectivity, averaged over the 2014-EWP period of 5 May-6 June 2014. We first point out that the prediction of $30-\mathrm{dBZ}$ reflectivity at $1-\mathrm{km}$ and $15-\mathrm{min}$ resolution is a very challenging task. This is clear from the relatively low ETS values exhibited by simple statistical methods such as persistence and advection, shown as benchmarks in Fig. 7a. The vLAPS initialized forecast is clearly competitive with both benchmarks, and beyond 1-h lead time outperforms even the more competitive advection scheme during this convectively very active period. This is an indication that with high-quality initial conditions, NWP guidance is becoming potentially relevant for nowcasting and very short-range forecasting applications. Additional Warn-On-Forecast and nowcasting type vLAPS results from the 2014-EWP and other experiments will be presented in a separate report.

THREE-DIMENSIONAL CLOUD ANALYSIS.

An alternative way of assessing the quality of the analysis and forecast of hydrometeorological variables is via the comparison of observed and simulated clouds. Recently, the vLAPS software was expanded with a raytracing procedure to construct simulated all-sky cloud imagery produced by the LAPS 3D cloud analysis, and vLAPS/ARW forecasts. To monitor the quality of LAPS analyses, simulated cloud images are compared in real time with all-sky imagery obtained from ground-based cameras in either a polar or cylindrical projection. Assessment of the cloud brightness and darkness patterns reveals cloud types, organizational patterns, and thicknesses, validating cloud and precipitation hydrometeor concentrations. A recent example of all-sky imagery is shown in Fig. 8. This example shows good comparison between simulated clouds with finescale cloud structures and all-sky imagery. There are many examples showing this good performance, but also some less favorable examples. The development of a new, fully variational cloud analysis module is expected to make the comparison more consistent. Interested readers are referred to a real-time display of all-sky images available online at http://laps.noaa.gov/allsky/allsky.cgi.

An accurate finescale analysis of cloud and precipitating hydrometeors is essential for an accurate finescale, short-term forecast. Figure 9 shows a 15-min forecast example for the Moore tornado case during 2013-EWP. When looking at the associated forecast cloud loop in the online supplement (DOI:I0.II75 /BAMS-D-I3-00|85.2), one can observe a satisfying continuity between the model initialization and the first few minutes of the forecast, indicating an acceptable balance between analysis variables in this example. 


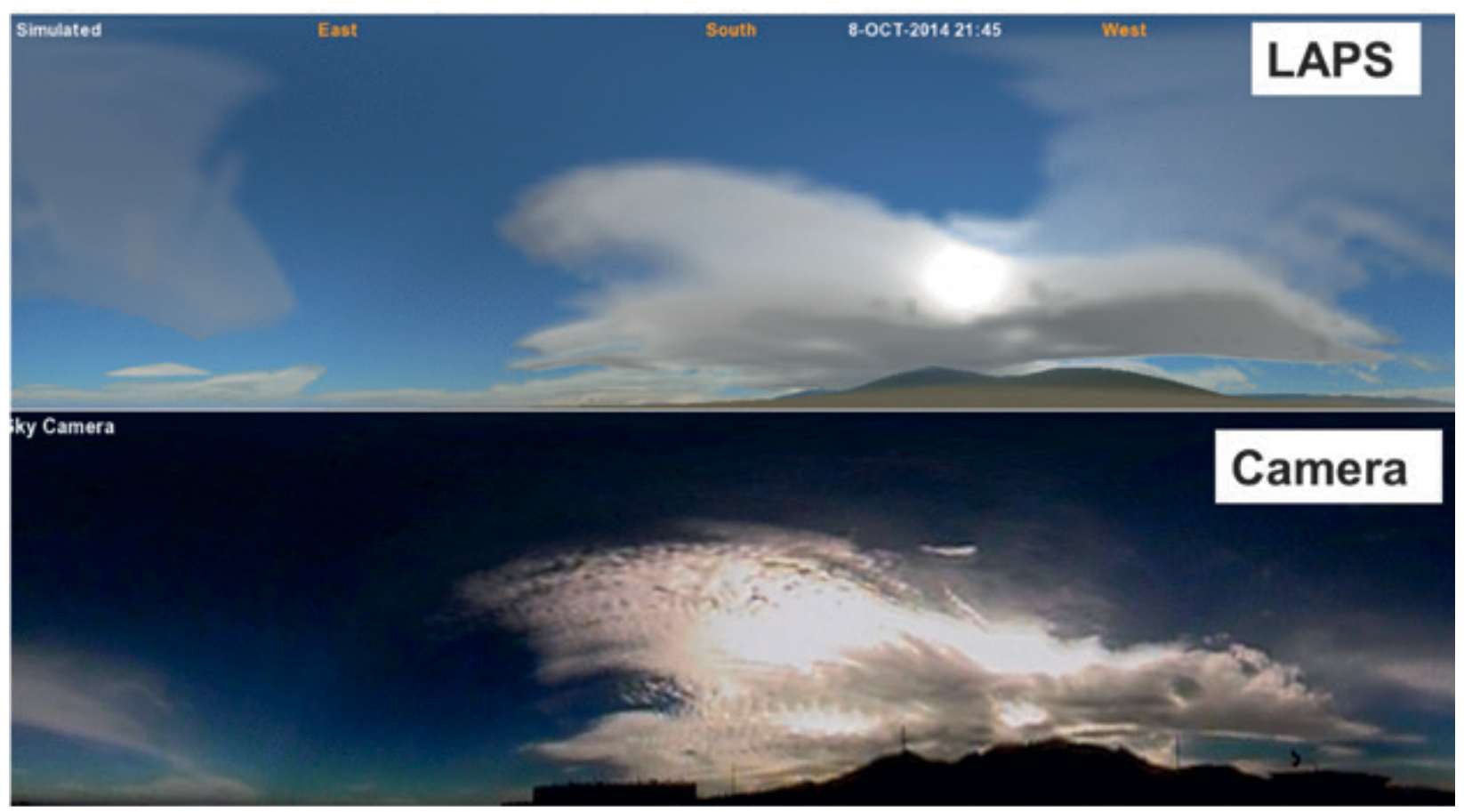

FIG. 8. Comparison of a simulated all-sky cloud image from a 500-m grid spacing 3D LAPS analysis, and an all-sky camera image (Moonglow camera is mounted atop of David Skaggs Research Center in Boulder, CO) for 2I45 UTC 8 Oct 2014 (real-time all-sky images are available online at http://laps.noaa .gov/allsky/allsky.cgi).

The comparison of observed and simulated all-sky images can also assist the development of high-resolution analysis and vLAPS/ARW forecast products. This technique helped, for example, to improve the consistency of cloud albedo and microphysical variables, and to reduce systematic satellite navigation errors, including parallax. GSD and its collaborators also plan to use all-sky cameras directly in data assimilation to help fill observational gaps at small scales.
CLOSING REMARKS. LAPS, including its new variational version (vLAPS), has been developed as a national and international community effort, led by the Global Systems Division of NOAA/ESRL. The development is motivated by the societal need for high-quality, high-resolution, and low-latency data assimilation capabilities in support of forecaster situational awareness, and for Warn-On-Forecast guidance in nowcasting and convective initiation in

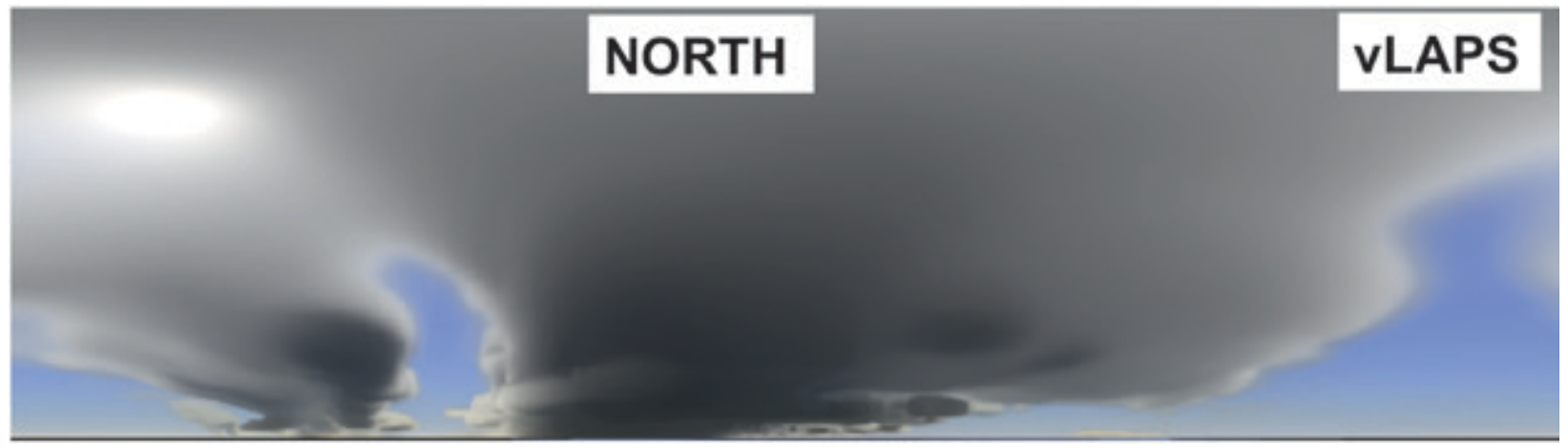

Fig. 9. Simulated Moore tornado storm from a I-km vLAPS/ARW forecast initialized using vLAPS 3D analyses at 1900 UTC. This is a 15-min forecast valid at 1915 UTC 20 May 2013 [animation of I-km vLAPS/ARW 2-h forecast for simulated Moore tornado is shown in the online supplement (DOI:I0.|I75/BAMS-D-I3-00|85.2)]. Camera image is not available for comparison for the simulated Moore tornado storm. 
support of NOAA's "Weather-Ready Nation" initiative (www.nws.noaa.gov/com/weatherreadynation/files /nws_wrn_roadmap_final_aprill7.pdf).

The Experimental Warning Program (2013-EWP) of the Hazardous Weather Testbed was used as a platform for a real-time test of the utility of frequently updated high temporal and spatial resolution vLAPS analyses (in support of situational awareness) and ensuing forecasts (in support of nowcasting). In several severe weather situations, forecasters positively commented on vLAPS capabilities while identifying areas that called for further improvements.

The 3D vLAPS analysis capability is being ported in 2015 onto AWIPS-II workstations to support situational awareness in NWS operations, while in collaboration with Massachusetts Institute of Technology-Lincoln Laboratory, its $2 \mathrm{D}$ configuration is being transitioned to Federal Aviation Administration nowcasting operations (Mehta et al. 2013).

Current efforts focus on the development of a cloud analysis module for variational assimilation applications. This module will utilize improved forward models for the assimilation of all remotely sensed and in situ observations related to the cloud microphysical variables (i.e., cloud liquid and ice, as well as precipitating hydrometeors), and include advanced thermodynamic and microphysical constraints. The cloud analysis module is developed using objectoriented design principles so beyond LAPS it can also be integrated into any variational data assimilation scheme, such as the Gridpoint Statistical Interpolation analysis system (GSI) for the initialization of very finescale nonhydrostatic global models. Future work will focus on possibly incorporating aspects of the vLAPS analysis (cloud analysis, etc.), where unique, into the community-based GSI analysis package.

ACKNOWLEDGMENTS. This work would not have been possible without the enthusiastic support of the broader LAPS user and development communities. The authors thank John Osborn of Cherokee Nation Technologies for his careful editorial review of this manuscript. The authors thank the following individuals for their contributions in various capacities: Lans Rothfusz, Travis Smith, Kristin Calhoun, and Gabe Garfield (HWT support from NOAA/NSSL); Robert Lipschutz (data transfer arrangements from NOAA/ESRL/GSD); and H. Frank J. Guseman, N. Hampshire, A. Hatzos, M. Austin, J. Kurtz, C. Leonardi, B. Mazur, E. Ostuno, H Tuschy, E. Martello, A. Sears, J. Wesely, A Zimmerman, K. White HUN, and J. McCormick (participating as forecasters in the HWT-2013 EWP experiments). We thank Pablo Santos, an anonymous reviewer, and the editor (Jeff Waldstreicher) for their constructive reviews that significantly improved the manuscript.

\section{APPENDIX: ACRONYMS.}

\section{CWA County Warning Area}

GSD Global Systems Division

HRRR High Resolution Rapid Refresh, NOAA/NWS operational weather prediction system

LAPS Local Analysis and Prediction System, also referred to as traditional LAPS

SBCAPE Surface-based CAPE

vLAPS Variational version of LAPS, also known as STMAS (Space and Time Multiscale Analysis System). This older acronym is equivalent to vLAPS.

\section{FOR FURTHER READING}

Albers, S., J. McGinley, and D. Birkenheuer, 1996: The Local Analysis and Prediction System (LAPS): Analyses of clouds, precipitation, and temperature. Wea. Forecasting, 11, 273-287, doi:10.1175/1520 -0434(1996)011<0273:TLAAPS>2.0.CO;2.

Briggs, W. L., 1987: A Multigrid Tutorial. Society for Industrial and Applied Mathematics; Lancaster Press, 88 pp. Clark, A. J., and Coauthors, 2012: An overview of the 2010 Hazardous Weather Testbed Experimental Forecast Program Spring Experiment. Bull. Amer. Meteor. Soc., 93, 55-74, doi:10.1175/BAMS-D-11-00040.1.

Etherton, B., and P. Santos, 2006: The effect of using AWIPS LAPS to locally initialize the workstation ETA. Natl. Wea. Dig., 30, 49-60.

Hiemstra, C., G. Liston, R. Pielke Sr., D. Birkenheuer, and S. Albers, 2006: Comparing Local Analysis and Prediction System (LAPS) assimilations with independent observations. Wea. Forecasting, 21, 1024-1040, doi:10.1175/WAF961.1.

Jiang, H., Y. Xie, S. Albers, and Z. Toth, 2014: Testing convective scale data assimilation in severe storm cases using Variational Local Analysis and Prediction System (vLAPS). The 2014 World Weather Open Science Conf., Montreal, Canada.

Liu, C., Q. Xiao, and B. Wang, 2008: An ensemblebased four-dimensional variational data assimilation scheme. Part I: Technical formulation and preliminary test. Mon. Wea. Rev., 136, 3363-3373, doi:10.1175/2008MWR2312.1. 
McGinley, J., S. Albers, and P. Stamus, 1991: Validation of a composite convective index as defined by a real-time local analysis system. Wea. Forecasting, 6, 337-356, doi:10.1175/1520-0434(1991)006<0337:VO ACCI>2.0.CO;2.

Mehta, V., T. Reynolds, M. Ishutkina, D. Joachim, Y. Glina, S. Troxel, B. Taylor, and J. Evans, 2013: Airport surface traffic management decision support: Perspectives based on tower flight data manager prototype. The National Technical Information Service, product code PB2013108463.

Raytheon, 2013: AWIPS System Manager's Manual: AWIPS II Operational Build 13.4.1. Document No. AWP.MAN.SMM.A2-OB13.4.1.

Skamarock, W., J. Klemp, J. Dudhia, D. Gill, D. Barker, W. Wang, and J. Powers, 2008: A description of the Advanced Research WRF version 3. NCAR Tech Note, NCAR/TN-475+STR, 113 pp.

Smith, A., and R. Katz, 2013: U.S. billion-dollar weather and climate disasters: Data sources, trends, accuracy and biases. Nat. Hazards, 67, 387-410, doi:10.1007/ s11069-013-0566-5.

Stensrud, D., and Coauthors, 2009: Convectivescale warn-on-forecast system: A vision for 2020. Bull. Amer. Meteor. Soc., 90, 1487-1499, doi:10.1175/2009BAMS2795.1.

Thompson, R. L., R. Edwards, and C. M. Mead, 2004: An update to the supercell composite and significant tornado parameters. 22nd Conf. on Severe Local Storms, Hyannis, MA, Amer. Meteor. Soc, P8.1 [Available online at https://ams.confex.com/ams /pdfpapers/82100.pdf.]

Toth, Z., S. Albers, and Y. Xie, 2012: Analysis of finescale weather phenomena. Bull. Amer. Meteor. Soc., 93, ES35-ES38, doi:10.1175/BAMS-D-11-00148.1.

—, M. Tew, D. Birkenheuer, S. Albers, Y. Xie, and B. Motta, 2014: Multiscale data assimilation and forecasting. Bull. Amer. Meteor. Soc., 95, ES30-ES33, doi:10.1175/BAMS-D-13-00088.1.

Wilks, D. S., 1995: Statistical Methods in the Atmospheric Sciences: An Introduction. Academic Press, 467 pp.

Xie, Y., S. Koch, J. McGinley, S. Albers, P. Beringer, M. Wolfson, and M. Chan, 2011: A space-time multiscale analysis system: A sequential variational analysis approach. Mon. Wea. Rev., 139, 1224-1240, doi:10.1175/2010MWR3338.1.

—, H. Jiang, S. Albers, L. Wharton, and T. Barker, 2014: Transitioning the surface version of variational LAPS into FAA operations. 30th Conf. on Environmental Information Processing Technologies, Atlanta, GA, Amer. Meteor. Soc., 2.6.
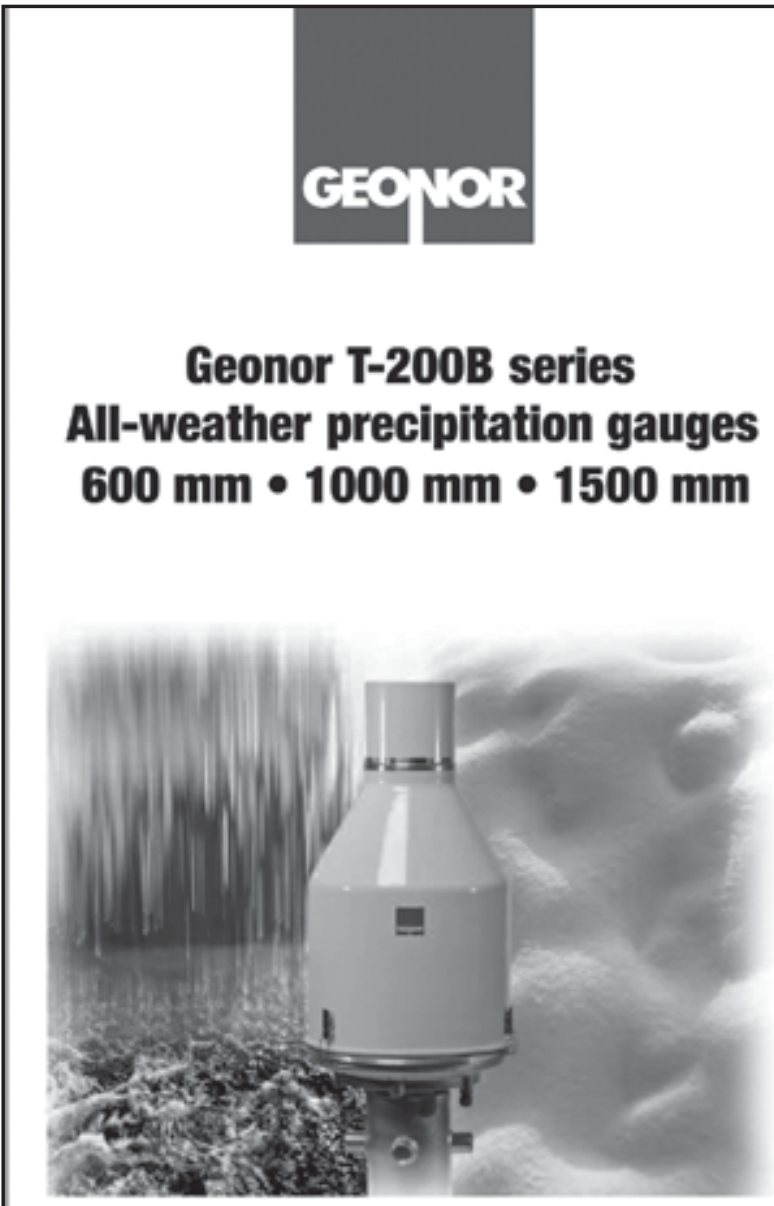

- More than 25 years of field use - No moving parts

- Easy installation and maintenance

- No internal heating necessary - Precipitation intensity can be calculated

- Interfaces to most data acquisition systems

$$
\text { Proven long term reliability }
$$

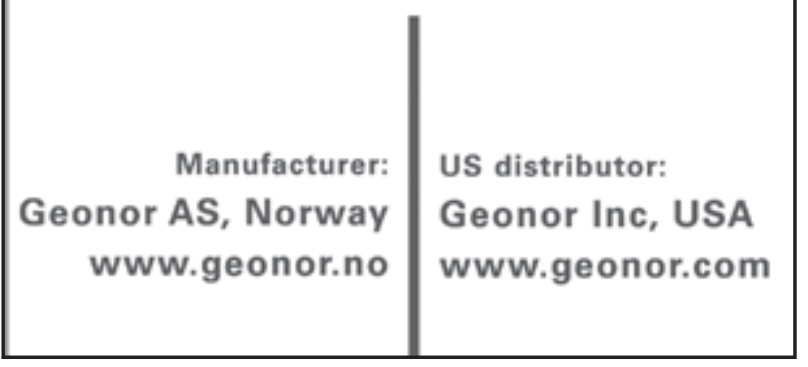


AMS titles now

avallable as eBooks

at springer.com

\section{AMS BOOKS}

\section{RESEARCH APPLICATIONS HISTORY}

www.ametsoc.org/amsbookstore

\section{Springer}

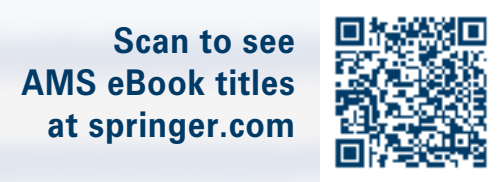

Q) Springer

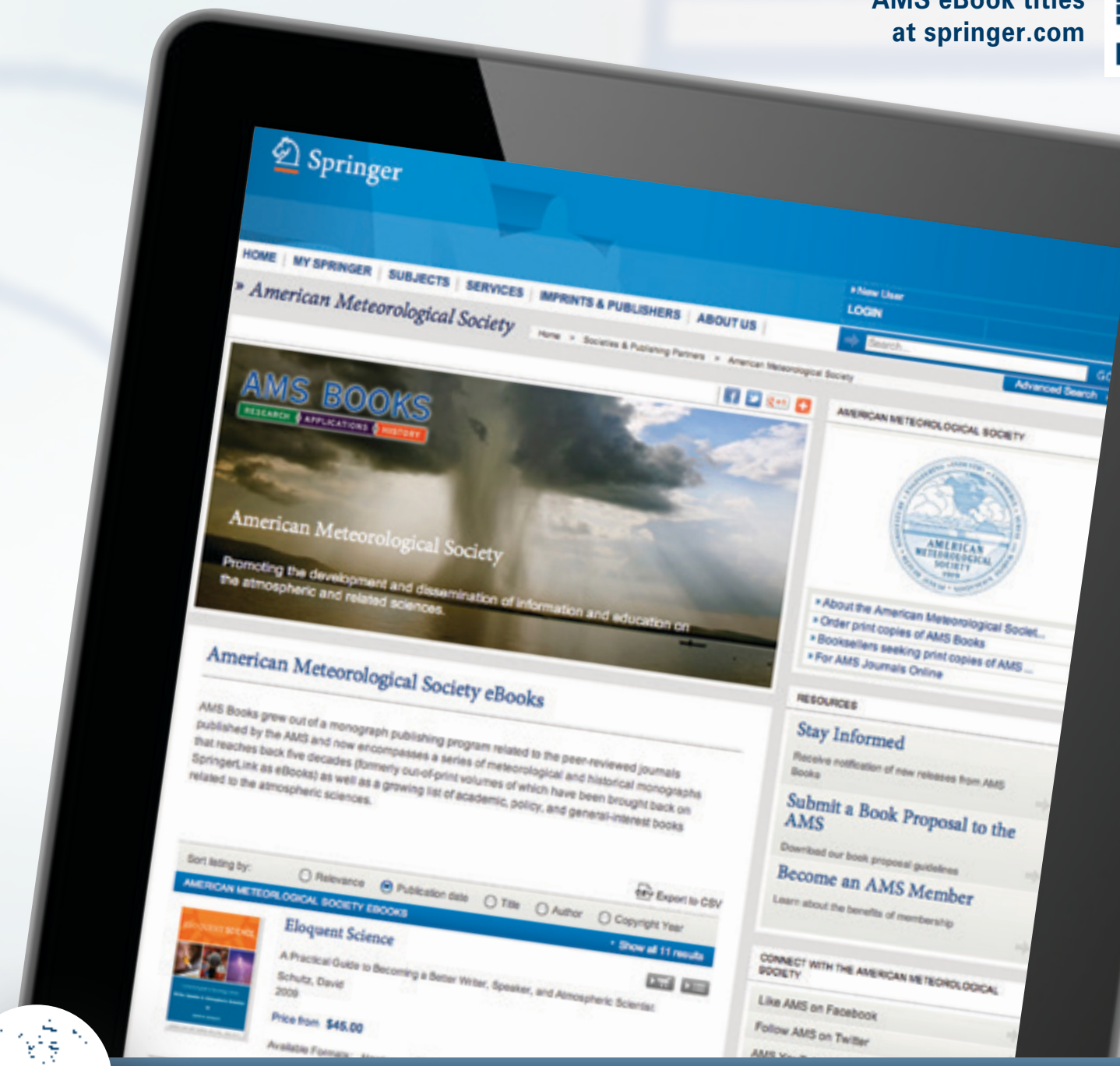

A MER ICA N METEOROLO G I C A L S O C I E T Y 